\title{
A Critical Analysis of Polymersome Therapeutics: From Laboratory to Large-Scale Production
} \author{
and Adriano Marim de Oliveira ${ }^{1 *}$ \\ ${ }^{1}$ Instituto de Pesquisas Tecnológicas do Estado de São Paulo (IPT), Bionanomanufacturing Center, Brazil \\ ${ }^{2}$ Instituto de Química de São Carlos, Universidade de São Paulo, Brazil \\ ${ }^{3}$ Instituto de Ciências Biomédicas, Universidade de São Paulo, Brazil \\ ${ }^{4}$ Instituto Nacional de Ciência e Tecnologia de Bioanalítica-INCTBio, Brazil
}

Beatriz Nogueira Messias de Miranda ${ }^{1,2}$, Wesley Luzetti Fotoran ${ }^{3}$, Gerhard Wunderlich ${ }^{3}$, Emanuel Carrilho ${ }^{2,4}$

Submission: March 03, 2018; Published: May 21, 2018

*Corresponding author: Adriano Marim de Oliveira, Instituto de Pesquisas Tecnológicas do Estado de São Paulo (IPT), Bionanomanufacturing Center, São Paulo-SP, Brazil, Email: miranda@ipt.br

\section{Introduction}

\section{Polymersomes as a synthetic evolution of liposomes}

Vesicular compartments are responsible for an organized separation within the cell and were crucial to the generation of life and the evolution. Vesicles produced by self-assembling of amphiphilic lipids arose as a promising technology for mimicking bio-available compartments, as well as its advantages related to chemical gradients, energy storage, stimuli responsiveness, and others. After the first description of liposomes in the mid-60s, they became present in many biotechnological applications. In 2005, the FDA approved the first liposome-based drug delivery carrier, Doxil@ (doxorubicin $\mathrm{HCl}$ liposome injection, Janssen Products, LP). Over the years, the use of an inert polymer as an adjuvant in liposome constitution was vital, and polyethylene glycol (PEG) provided improvements in biodistribution with minimal side effects [1], both of which relevant characteristics for drug delivery [2,3]. Therefore, polymersomes, comprised of amphiphilic block copolymers (BCPs), emerged as a promising alternative to liposomes [4,5]. Both present analog lamellar membrane structure. Polymer vesicles display modifications in structural features of self-assembled vesicles, and therefore show enhanced stability compared with liposomes. Moreover, the high diversity and versatility of synthetic polymers enables the modulation of physicochemical properties related to membrane thickness, composition, permeability, stimuliresponsiveness, particle morphology and size, according to the desired application [6-12]. He high stability and robustness of these structures, however, could be addressed as a disadvantage towards becoming a functional drug delivery system. For this reason, stimuli-responsive polymersomes appear as an alternative to deliver the inside content upon demand, using, for instance $\mathrm{pH}$, temperature, and osmotic differences, or ultrasound as an exogenous stimulus [13,14]. Moreover, biocompatible polymersomes were already tested in vivo as drug carriers and demonstrated its great potential for therapeutic applications $[15,16]$.
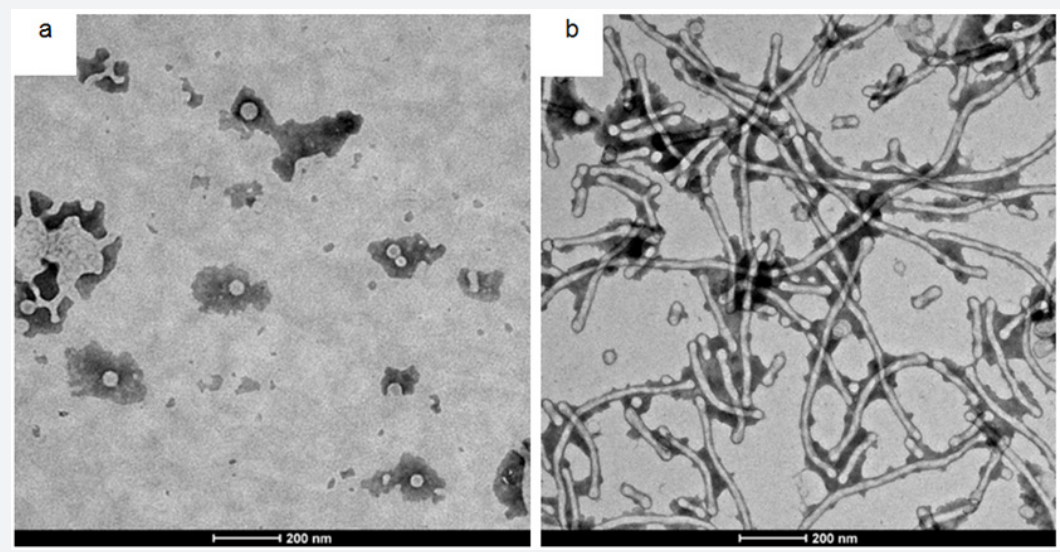

Figure 1: TEM images of PEG-b-PLA polymersomes prepared by film hydration followed by sonication without (a) and with (b) drug content. 


\section{Loading polymersomes with cargos and its structural consequences}

Regarding drug delivery, the existence of an aqueous core - like liposomes - enables loading of hydrophilic drugs while hydrophobic drugs can be included within their amphiphilic membranes [6-11,17]. While the concomitant use of different active principles may seem an interesting strategy for disease treatment, the interaction between the external molecule and the block copolymer branches may interfere in the morphology of the particle, which is illustrated in Figure 1. Such interference may be one of the drawbacks regarding self-assembly vesicle formation with the drug acting similarly to a blend of substances producing different morphologies, such as tubes, worm-like micelles or other polymeric aggregates [15].

The self-assembling or self-organization process depends on the interfacial energy related to the hydrophilic/hydrophobic interface, that tends to compensate the loss of entropy due to the polymer linkage [12]. Unfortunately, polymersomes production is not trivial. Key experimental conditions such as the nature of the solvent, type and concentration of the polymer, water disponibility, temperature and external shear forces, in addition to macromolecular parameters appear to have great influence on the self-assembling process, affecting e.g., aggregate morphology and size [1]. Predictions of aggregate morphologies were proposed based mainly on macromolecular parameters such as hydrophilic and hydrophobic balance (hydrophilic weight fraction $f$, for PEG hydrophobic parts), in which the increase of $f$ seems to favor spherical or worm-like micelles, while the decrease produces hollow structures, including vesicles [15]. Nevertheless, such a prediction cannot be considered as universal, and the effective outcome depends strongly on the polymer chain structure and characteristics [1]. Moreover, even though BCPs can also self-assemble into vesicles when hydrated, commonly used preparation methods for polymersomes rely on (i) film hydratation approaches--what is somewhat inefficient or very time consuming requiring up to one month if used solely -, or (ii) bulk methods, such as the solvent-switching and double emulsion approaches--which require the use of organic solvents, often not suitable for biomedical applications $[9,18]$.

Further, the size plays an important role, especially for intravenous injection, permeability, and retention (EPR effect). For that reason, techniques well established for liposomes that improve homogeneity and size (post-formation resizing) including extrusion through polycarbonate filters, freezethaw cycles and/or, sonication are applied for the same intent $[2,19,20]$. Since the use of membrane extrusion is timeconsuming, expensive, and risky (clogging of the system is a frequent phenomenon), it is limited to the laboratory scale. This may be achieved by the use of other techniques such as sonication or freezing, but still, rely on high energy input requirements.
Clearly, a major drawback of this technology is the preparation step, which is time-consuming and difficult for highthroughput setups. This may be the reason why there are still no commercially available products based on polymer vesicles.

\section{New methods for scaling-up the production of polymersomes}

A first report discussing the value of developing industryscale polymersome production techniques was by published Poschenrieder et al. [21] who described a fundamental study regarding polymersome production via the ethanol method in a stirred-tank reactor [21,22]. Even though it was an important contribution to the field, such an approach may not be universally used as it still depends on the BCP's characteristics. Novel microfluidic methods for polymersome preparation techniques have emerged and since then, efforts have been concentrated mainly in device parallelization for industrial applications [23]. Devices such as a tandem emulsification device provide a promising alternative.

The fact that novel protocols for scaling-up are emerging indicates that the field is moving forward. One has to keep in mind that it took almost four decades until the approval of the first FDA-approved liposomal-based drug formulation and polymersomes exist only for two decades. In order to move closer to commercialization, significant developments are necessary in the process of self-assembly either for bulk production or for microfluidic production in industrial scale. Breakthroughs in this direction are expected.

\section{Acknowledgement}

This work was funded in part by CNPq (207254/2014-1), by the Institute for Technological Research, IPT, and the Institute for Technological Research Foundation, FIPT, for infrastructure and a fellowship for B.N.M.M. The National Institute for Science and Technology in Bioanalytics - INCTBio kindly acknowledges FAPESP (grant \# 2014/50867-3) and CNPq (grant \# 465389/2014-7) for their support.

\section{References}

1. Dionzou M (2016) Comparison of methods for the fabrication and the characterization of polymer self-assemblies: what are the important parameters? Soft Matter 12.

2. Lee JC, Bermudez H, Discher BM, Sheehan MA, Won YY, et al. (2001) Preparation, stability, and in vitro diblock copolymers. Biotechnol Bioeng 73: 135-145.

3. Bedu-Addo FK, Tang P, Xu Y, Huang L (1996) Effects of polyethyleneglycol chain length and phospholipid acyl chain composition on the interaction of polyethyleneglycol-phospholipid conjugates with phospholipid: implications in liposomal drug delivery. Pharmaceutical research 13: $710-717$.

4. Zhang L, Eisenberg A (1995) Multiple morphologies of "Crew-Cut" aggregates of polystyrene-b-poly(acrylic acid) block copolymers. Science 268: 1728-1731. 
5. Discher BM (1999) Polymersomes: Tough vesicles made from diblock copolymers. Science 284: 1143-1146.

6. Kabanov V, Bronich TK, Kabanov VY (1998) Spontaneous formation of vesicles from complexes of block ionomers and surfactants. J Am Chem Soc 120: 9941-9942.

7. Discher DE, Eisenberg (2002) A Polymer vesicles. Science 297: 967973.

8. Meng FH, Hiemstra C, Engbers GHM, Feijen J (2003) Biodegradable polymersomes. Macromolecules 36: 3004-3006.

9. Mai Y, Eisenberg A (2006) Self-assembly of block copolymers. Chem Soc Rev 41: 5969.

10. Discher DE, Ahmed F (2006) Polymersomes. Annu Rev Biomed Eng 8: 323-341.

11. Balasubramanian V, Herranz-Blanco B, Almeida PV, Hirvonen J, Santos HA (2016) Multifaceted polymersome platforms: Spanning from self-assembly to drug delivery and protocells. Progress in Polymer Science 60: 51-85.

12. Meng F, Zhong Z, Feijen J (2009) Stimuli-responsive polymersomes for programmed drug delivery. Biomacromolecules 10: 197-209.

13. Liu F, Urban MW (2010) Recent advances and challenges in designing stimuli-responsive polymers. Prog Polym Sci 35: 3-23.

14. Ahmed F, Discher DE (2004) Self-porating polymersomes of PEG-PLA and PEG-PCL: Hydrolysis-triggered controlled release vesicles. J Control Release 96: 37-53.
15. Pegoraro C, Cecchin D, Gracia LS, Warren N, Madsen J, et al. (2013) Enhanced drug delivery to melanoma cells using PMPC-PDPA polymersomes. Cancer Lett 334: 328-337.

16. Rodríguez G (2011) Polymersomes: smart vesicles of tunable rigidity and permeability. Soft Matter.

17. Li M, Lv S, Tang Z, Song W, Yu H, et al. (2013) Polypeptide/doxorubicin hydrochloride polymersomes prepared through organic solvent-free technique as a smart drug delivery platform. Macromol Biosci 13: 1150-1162.

18. Akbarzadeh A (2013) Liposome: classification, preparation, and applications. Nanoscale Res Lett 8: 102.

19. Hickey RJ (2014) Size-controlled self-assembly of super paramagnetic polymersomes. ACS Nano 8: 495-502.

20. Poschenrieder ST, Wagner SG, Castiglione K (2016) Efficient production of uniform nanometer-sized polymer vesicles in stirred-tank reactors. J Appl Polym Sci 133: 1-10.

21. Poschenrieder ST, Schiebel SK, Castiglione K (2017) Polymersomes for biotechnological applications: Large-scale production of nano-scale vesicles. Eng Life Sci 17: 58-70.

22. Shum HC, Kim JW, Weitz DA (2008) Microfluidic fabrication of monodisperse biocompatible and biodegradable polymersomes with controlled permeability. J Am Chem Soc 130: 9543-9549.

23. Eggersdorfer ML (2017) Tandem emulsification for high-throughput production of double emulsions. Lab Chip 17: 936-942.

\section{Your next submission with Juniper Publishers} will reach you the below assets

- Quality Editorial service

- Swift Peer Review

- Reprints availability

- E-prints Service

- Manuscript Podcast for convenient understanding

- Global attainment for your research

- Manuscript accessibility in different formats

( Pdf, E-pub, Full Text, Audio)

- Unceasing customer service

Track the below URL for one-step submission https://juniperpublishers.com/online-submission.php 